\title{
DISFUNÇÕES TEMPOROMANDIBULARES E FATORES PSICOSSOCIAIS: UMA ABORDAGEM DIAGNÓSTICA
}

Leandro VIEIRA; Lilian CUSTÓDIO

Pacientes com Disfunção Temporomandibulares (DTM), relatam da queixa de dor nos maxilares, otalgias, cefaléias, e apresentam movimentos mandibulares limitados ou assimétricos (MANFREDI, 2001). O entendimento da gênese da dor, das condições moduladoras, dos mecanismos inibidores excitatórios, dos efeitos secundários dos sintomas associados e das reações físicas e emocionais que ocorrem nos humanos são fatores importantes no diagnostico da dor (OKESON, 1998). Atualmente alguns autores preconizam métodos que podem confirmar o diagnóstico da dor, ou até mesmo questionários préestabelecidos para diagnosticar as DTM, a exemplo do "Questionário para Triagem para Dor Orofacial e DTM" da Academia Americana de Dor Orofacial. Esse estudo objetiva analisar qualitativamente os métodos empregados no diagnóstico das DTM citados na literatura correlacionando-os com a influência dos Fatores Psicossociais e, sua importância no estabelecimento de um diagnóstico efetivo para as DTM relacionadas a esses fatores. 